Chen, C., Zhang, L., Luczak, T., Smith, E., \& Burch, R. (2019). Using Microsoft HoloLens to improve memory recall in anatomy and physiology: A pilot study to examine the efficacy of using augmented reality in education. Journal of Educational Technology Development and Exchange, 12(1), 17-31

\title{
Using Microsoft HoloLens to improve memory recall in anatomy and physiology: A pilot study to examine the efficacy of using augmented reality in education
}

\author{
Chen Chen \\ Mississippi State University \\ Lei Zhang \\ Mississippi State University \\ Tony Luczak \\ Mississippi State University \\ Eboni Smith \\ Mississippi State University \\ Reuben Burch \\ Mississippi State University
}

\begin{abstract}
This paper explores the use of augmented reality (AR) to improve memory recall and learning experiences in human anatomy and physiology. In particular, the opportunity to assess new computer technologies to improve learning environments may allow for an improvement in self-efficacy and a reduction in test anxiety. Twenty-two undergraduates participated in one of two study groups, the Microsoft HoloLens group (HLNS) or the traditional projector-based Microsoft Power Point group (PPT). Each group completed a five-minute, three-subject anatomy identification and brain physiology memory test. After a three-minute time delay, participants completed a fill-in-the-blank anatomy identification test and brain physiology question test, followed by questionnaires for systems self-efficacy and test anxiety. Results indicated the PPT group significantly outperformed the HLNS group in the brain lobe identification portion of the exam and had reported higher mean test anxiety scores (though not high enough to be considered unhealthy levels). However, the HLNS group showed a significantly higher preference to the learning experience compared to the PPT group based on the systems self-efficacy questionnaire. This pilot study demonstrates an opportunity for the HLNS to use used in learning environments to improve the psychological aspects of studying and test taking.
\end{abstract}

Keywords: Augmented Reality Technology, Microsoft HoloLens, Anatomy, Physiology, Selfefficacy, Anxiety 


\section{Introduction}

Anxiety can foster many emotional and physiological responses, including increases in heart rate, upset stomach, worrying, phobias, and fear (Walshe et al., 2003). Anxiety-based symptoms can derive from experiences, such as car accidents (Rizzo et al., 2014), evaluative tests, and traumatic life and death situations such as war (Lawrence, De Silva, $\&$ Henley, 2010). The treatment of anxietybased disorders can be pharmacological, psychotherapeutic (Opriş et al., 2014), and computer-based alternatives such as virtual reality exposure therapy (VRET) (Lawrence, De Silva, \& Henley, 2010). Using computerbased therapy to overcome phobias and anxiety have seen comparable efficacy results in treatment of fear of spiders, flying, and heights when compared to traditional interventions (Moustafa et al., 2015). As processing speeds and interest in computer based wearable technology increases (Azuma, 1997), the development of augmented or mixed reality is potentially a new application for learning in the education field, specifically for medical intervention.

For a medical field like computer technology therapy, augmented reality (AR) places three dimensional (3D) virtual images into the users real, 3D environment in realtime by looking through the wearable glasses of the device (Botella et al., 2012). AR technology can be implemented widely in various learning media; one advantage of this technology that can be used in learning is the ability to provide $3 \mathrm{D}$ visualization to students. The application of using an AR device is derived from the developing concept of "positive psychology" which utilizes a holistic approach of positive experiences as therapy (Elangovan \& Ismail, 2014). The utilization of computer technologies can further create positive environments or experiences that traditional interventions cannot offer. Dunleavy, Dede, and Mitchell (2009) conducted a qualitative study and found that teachers who identified students as Attention Deficit Hyperactivity Disorder (ADHD) and unmotivated were $100 \%$ more engaged in the learning process during an AR simulation. Another application of computer based positive experience (Newman et al., 2011) was through "serious games". Serious games were part of the electronic games for psychotherapy (EGP) and had been used in conjunction with traditional interventions showing positive acceptance. Within cognitive behavior therapy, specific games have long been used resulting in positive outcomes when treating various anxiety disorders (Nist \& Diehl, 1990).

One of the technology advantages of AR is supporting how people study to retain information. Yuen, Yaoyuneyong, and Johnson (2011) listed an overview of five learningbased AR usage directions including: (a) AR books, (b) AR gaming, (c) discovery-based learning, (d) objects modeling, and (e) skills training for AR in education. Both the 2010 and 2011 Horizon Reports predict that AR will soon see widespread use on US college campuses (Johnson et al, 2010; Johnson et al, 2011). In one study, 68 students experienced a $3 \mathrm{D}$ realistic simulation of cell division, while 68 in the control group studied non-realistic simulation. The results indicated that the group who studied the $3 \mathrm{D}$ realistic simulation outperformed the control group in post-test and memory retention test scores (Horne-Moyer, et al. 2014). Antonioli, Blake, and Sparks (2012) found that using augmented storybooks led to more positive results as students were able to recall stories while exhibiting better reading comprehension. Augmented storybooks could especially help students who were less capable of comprehending text-based only materials. Physical movement is another component of engagement in AR tasks. A student who 
may struggle in the more common, stationary learning environment can become more actively involved in the kinesthetic nature employed by augmented tasks (Antonioli, Blake, and Sparks, 2012).

In addition to the inclusion of movement, further evidence shows that technology can create a more positive experience for the user when examining the effects of realistic simulation versus non-realistic simulation in learning cellular biology. Irwansyah et al. (2017) presented a case study using AR-based learning media on an Android device with positive results showing this type of solution has the potential to be applied to the learning of chemistry-based concepts especially those pertaining to molecular geometry material. Hannu Salmi, Thuneberg, and Vainikainen (2017) analyzed learning using AR technology and the motivational and cognitive aspects related to learning in an informal context. The data consisted of both cognitive tasks and selfreport questionnaires and were analyzed by Structural Equation Modeling (SEM) path analysis. The results showed that the AR experience was beneficial for pre-knowledge skills and the post-knowledge test.

Collins and Halverston (2018) presented that AR also relates to the just-in-time learning theory. This theory suggests that students learn information that they need to know now. They stressed that teachers should "reconceptualize" how they view learning and "rethink" what they should teach. AR allows educators to do both things by letting them use a new and engaging technology to view aspects of the real world in a different way. Enyedy, et al. (2012) presented a Learning through Play Project (LPP) by engaging six- to eight-year-old students in a series of scientific investigation of Newtonian force and motion via a series of AR activities. They then presented pre- and post-test results to demonstrate how young students were able to develop a conceptual understanding of force, net force, friction and two-dimensional motion after participating in the LPP curriculum.

In addition to learning, computer-based therapy (CBT) has shown to improve therapy results using multimedia (Wright et al., 1995), interactive voice response (Marks et al., 1998), hand-held computers (Newman et al., 1997), and virtual reality (Rothbaum et al., 1995), while creating high levels of user acceptance and satisfaction (Wright et al., 2002). However, there exists a high level of computer costs to "build out" comprehensive CBT environments and real-life scenarios in VR (Baus \& Bouchard, 2014). Baus and Bouchard (2014) have recommended that AR exposure-based therapy (ARET) can provide an efficacious therapy alternative in treating a variety of phobias, such as social and small animals, (Wrzesien, et al., 2011), improve self-efficacy (Wrzesien et al., 2013), while providing lower computer costs.

Thus, the purpose of this study is to build upon previous AR findings in learning and CBT through a pilot study of traditional PowerPoint teaching media and AR learning experience in recall and test taking experience.

\section{Experiment Objectives}

The aim of this experiment was to test the effectiveness of AR technology on memory recall and learning experiences. This study used the Microsoft (MS) Hololens (HLNS) AR technology based on its advanced capability versus other solutions (at the time of this study), the accessibility of its pre-loaded learning applications, and its availability to the research team. The study methodology was designed around the constraints imposed by the HLNS software application, HoloAnatomy, as the goal of this study was to demonstrate "off-the-shelf" capability versus the need to 
design completely new AR learning solutions.

For this study, students used the HLNS and the HoloAnatomy application to visually review several regions of human anatomy including (a) the gastrointestinal (GI) system, (b) select features of the heart, and (c) identification of brain lobes and their function (also delivered via audio recording). Another group of students participated in a traditional MS PowerPoint (PPT) representation of the same human anatomy regions including identical audio recording of the brain functions and to not create a modality-based confounding variable.

The primary hypothesis is that HLNS learning methods will result in higher exam scores, higher self-efficacy questionnaire results and lower test anxiety questionnaire results. The null hypotheses tested for this pilot study are that the distribution of questionnaire and exam scores will be the same across (a) test anxiety, (b) GI, (c) heart, (d) brain lobe, and (e) systems self-efficacy.

\section{Experiment Design}

\subsection{Participants}

Twenty-two Mississippi State University (MSU) undergraduate students (13 males, nine females) volunteered to participate in this study. To eliminate an order effect, 11 of the participants were randomly selected into the PPT learning group and 11 into the HLNS learning group. The study also separated the undergraduate students into two experience groups (Experience $1 \& 2$ ) based on the participants previous academic experience in studying human physiology. The Experience 1 group had no previous training in human physiology while the Experience 2 group participants had taken at least one human anatomy or human physiology class. Students who had previous class work in biology and/or human anatomy or physiology were separated equally into each group. There were 12 students in the Experience 1 group and 10 people in the Experience 2 group.

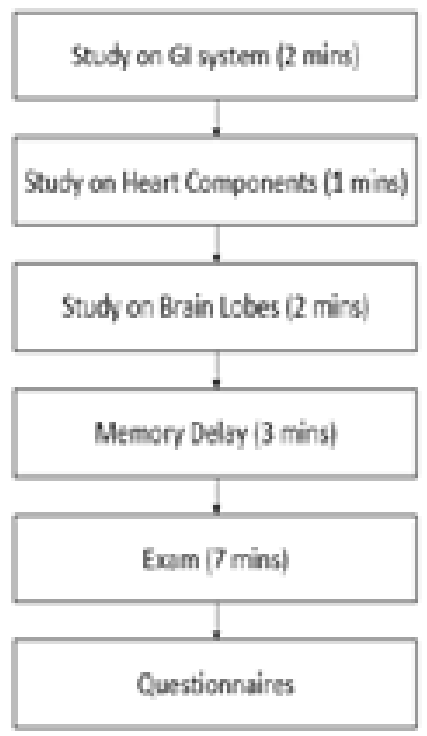

Figure 1. Flow diagram of experiment methodology 
Using Microsoft HoloLens to improve memory recall in anatomy and physiology:A pilot study to examine the efficacy of using augmented reality in education

Table 1 PPT and HLNS group participant and study details

\begin{tabular}{|c|c|c|}
\hline & PPT Group & HLNS Group \\
\hline Background & Undergraduate students & Undergraduate students \\
\hline Study Method & PPT & HLNS \\
\hline Study Content & $\begin{array}{c}\text { Gastrointestinal System; 4 Heart } \\
\text { Components; 6 Brain Lobes }\end{array}$ & $\begin{array}{c}\text { Gastrointestinal System; 4 Heart } \\
\text { Components; 6 Brain Lobes }\end{array}$ \\
\hline Study Duration & $2+1+2$ mins (total 5 mins) & 2+1+2 mins (total 5 mins) \\
\hline Memory Delay & 3 mins & 3 mins \\
\hline Exam Content & 3 parts of test (Fill in the blanks) & 3 parts of test (Fill in the blanks) \\
\hline Exam Duration & 7 mins & 7 mins \\
\hline Test Questionnaires & $\begin{array}{c}\text { Test anxiety questionnaire and } \\
\text { Self-efficacy questionnaire }\end{array}$ & $\begin{array}{c}\text { Test anxiety questionnaire and } \\
\text { Self-efficacy questionnaire }\end{array}$ \\
\hline
\end{tabular}

\subsection{Task and Apparatus}

Both groups followed same procedure: study, memory delay, exam, and questionnaires. Figure 1 displays the flow diagram of this study. Table 1 displays the details of this study for each group.

The PPT group participated in a traditional classroom setting complete with a projector showing two-dimensional images that presented the gastrointestinal system for two minutes (Figure 2), four heart components for one minute (Figure 3), and six brain lobes for two minutes (Figure 4) while brain functions were described from a pre-recorded female voice. A three-minute delay was given and then a test was administrated. The students had seven minutes to complete the memory test.

For the HLNS group, training and familiarization of navigation with the AR device was provided. The participants

\section{Gastrointestinal Tract}

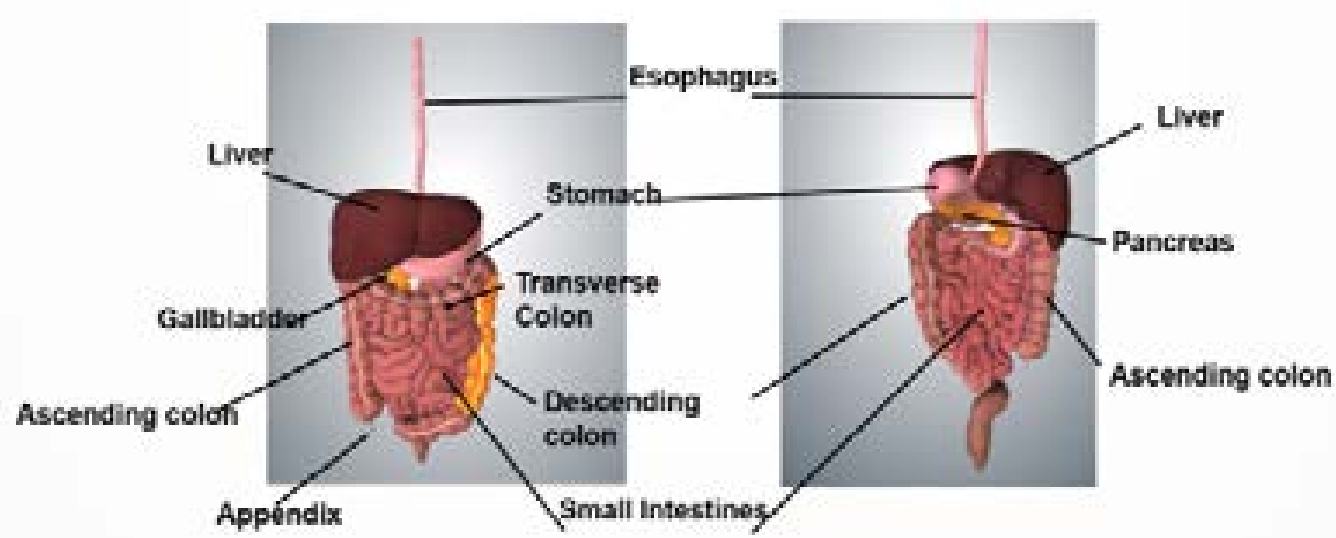

Figure 2. Two-minute visual display and related test of gastrointestinal system 


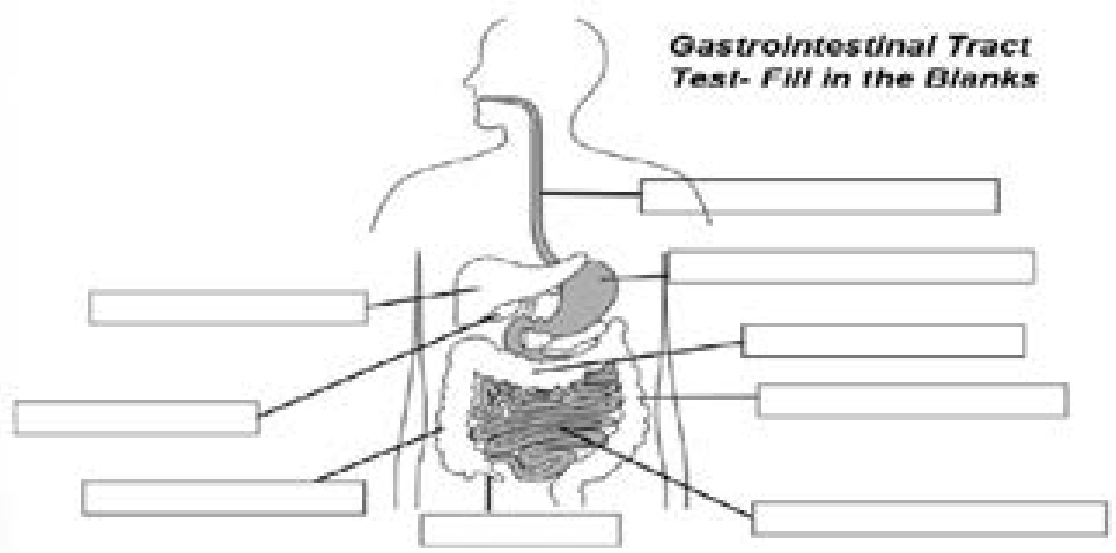

Figure 2. Two-minute visual display and related test of gastrointestinal system

were then instructed to go through the HoloAnatomy demonstration which included engaging with (a) the GI system for two minutes to memorize the organs, (b) the heart section for one minute to memorize the four components of the heart, and (c) the brain section for two minutes to complete the brain review. Participants from the HLNS groups were encouraged by the administrator to walk around the hologram and "air tap" on the
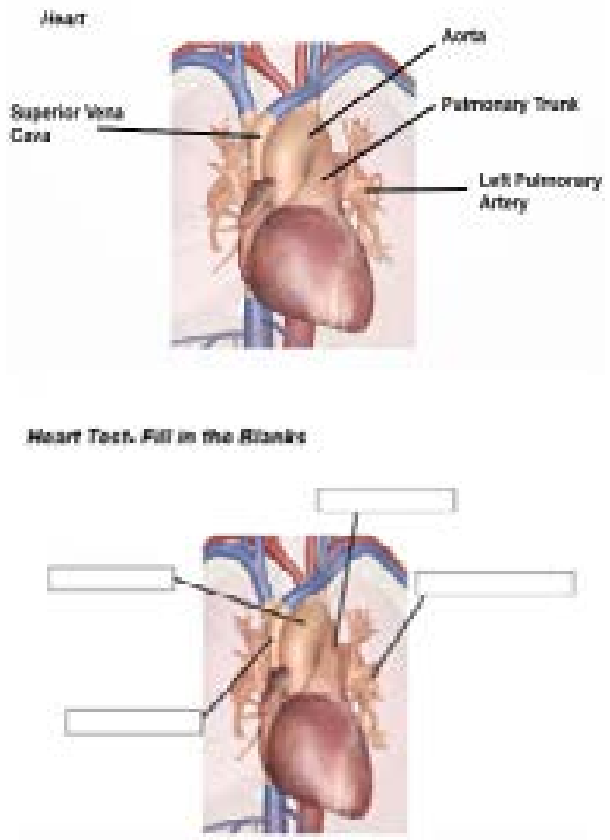

Figure 3. One-minute visual display and related test of four heart components 
lobes to hear the descriptive brain functions described by a pre-recorded female voice. Upon time completion, a three-minute delay was created before administration of the test. The test for the HLNS group was identical to the PPT group test and the students had seven minutes to complete it. The study content, study duration, test questions, and test duration of the PPT group and HLNS group were same.

A test anxiety questionnaire originally developed by Nist and Diehl (1990) was presented to both groups prior to the learning event. A systems self-efficacy questionnairea measure intended to assess children's general level of self-efficacy - was presented after the test to examine the confidence of learning. The academic self-efficacy subscale from the Self-Efficacy Questionnaire for Children (SEQ-C) assesses academic self-efficacy which refers to childrens' perceived capability to master academic affairs. The World Health Organization (WHO) defines as any person between ages 10 to 19 as a child. The age of the participants met the definition of WHO and so the SEQ-C was administered.

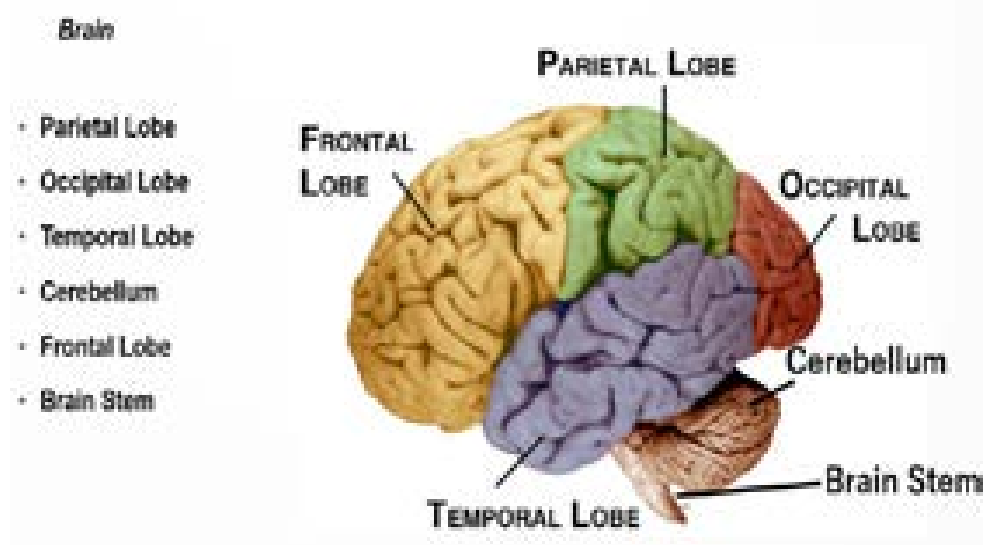

Brain Lobe- Fill in the Blanks
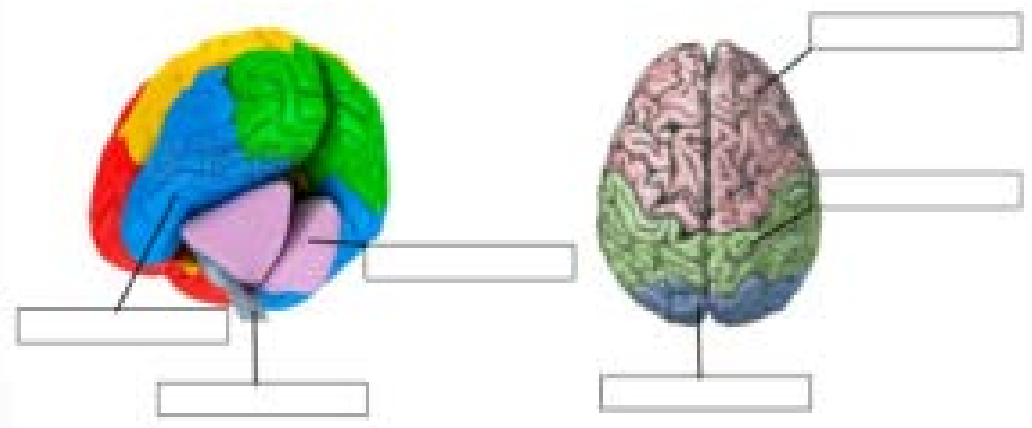

Figure 4. Two-minute visual study with one-minute auditory description of brain lobe function and related test of six brain lobes 


\section{Test Questions}

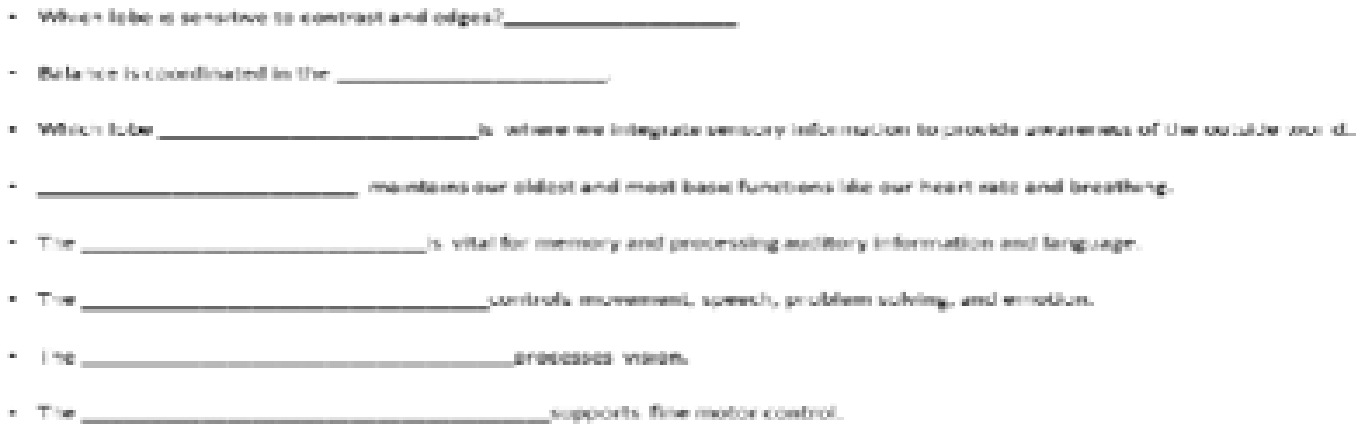

Figure 4. Two-minute visual study with one-minute auditory description of brain lobe function and related test of six brain lobes

SeAf-Efricacy Questivenairv for Childres isEQ-C)

\begin{tabular}{|c|c|c|c|c|c|c|}
\hline & & $\begin{array}{l}1 \\
\text { Not at all }\end{array}$ & 2 & 3 & 4 & $\begin{array}{l}5 \\
\text { Very }=11\end{array}$ \\
\hline & 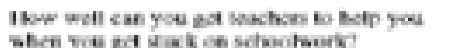 & 0 & O & 운 & 0 & O \\
\hline 2. & Thow wedl cas you espiese yeur epdetions & & & & 0 & \\
\hline & 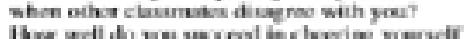 & 0 & 0 & 0 & 0 & 0 \\
\hline & 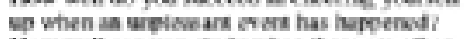 & 0 & 0 & 0 & 0 & 0 \\
\hline s. & 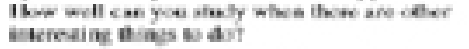 & 0 & 0 & 0 & 0 & 0 \\
\hline & 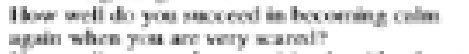 & o & 0 & 0 & 0 & 0 \\
\hline & 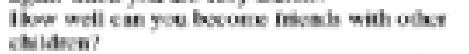 & 0 & 0 & o & 0 & 0 \\
\hline 7. & 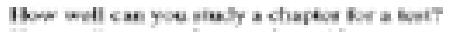 & 8 & o & o & 8 & б \\
\hline & 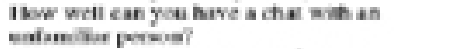 & 0 & 0 & 0 & 0 & 0 \\
\hline a. & 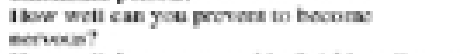 & 0 & 0 & 0 & 0 & 0 \\
\hline 10. & 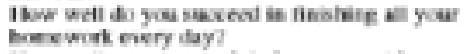 & $\%$ & 0 & 0 & 0 & 0 \\
\hline $\begin{array}{l}11 . \\
12 .\end{array}$ & 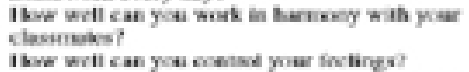 & $\stackrel{9}{\circ}$ & $\stackrel{0}{0}$ & $\stackrel{0}{0}$ & $\stackrel{9}{0}$ & $\stackrel{0}{6}$ \\
\hline 13. & 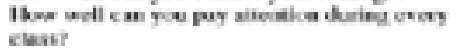 & 0 & 0 & 0 & 0 & 0 \\
\hline 14. & 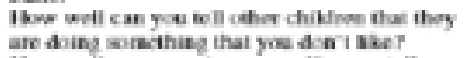 & 0 & 0 & 0 & 0 & 0 \\
\hline 15. & 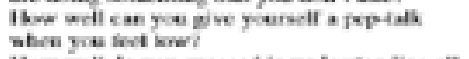 & o & 0 & $\circ$ & $\circ$ & $\odot$ \\
\hline 16. & 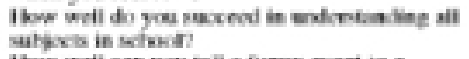 & \% & 0 & $\circ$ & $\theta$ & $\odot$ \\
\hline 17. & 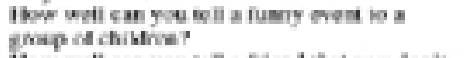 & 0 & 0 & 0 & 0 & 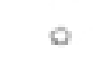 \\
\hline 18. & 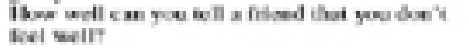 & 0 & 0 & 0 & 0 & 0 \\
\hline 19. & 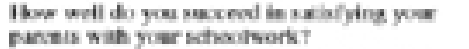 & 0 & 0 & 0 & 0 & 0 \\
\hline 20. & 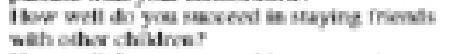 & $\mathrm{O}$ & 0 & 0 & 0 & 0 \\
\hline $\begin{array}{ll}21 . \\
22\end{array}$ & 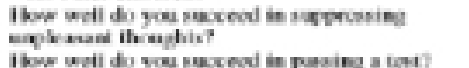 & $\stackrel{0}{0}$ & $\stackrel{8}{8}$ & $\stackrel{\circ}{0}$ & 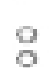 & $\stackrel{0}{0}$ \\
\hline 21. & 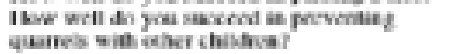 & o & 0 & o & 0 & 0 \\
\hline 24. & 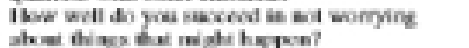 & 0 & 0 & 0 & 0 & 0 \\
\hline
\end{tabular}

(a) 
Using Microsoft HoloLens to improve memory recall in anatomy and physiology:A pilot study to examine the efficacy of using augmented reality in education

\section{Test Anxiety Questionasire}

Nist and Diehl (1990) develoged a loort queitiotnaire for determiting If a itudet experiences a mild or sever cale of thit anviety. To complete this evaluason. read

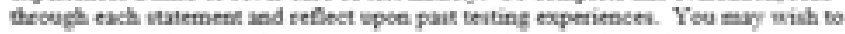
coesider all tevting experiences of focus ce a purticular subject (aitory. scienct. mak, etc.) cose a a time. Indicate bor eters each statement deicribei yeu by choosing a number troen cee to five as ourlined below.

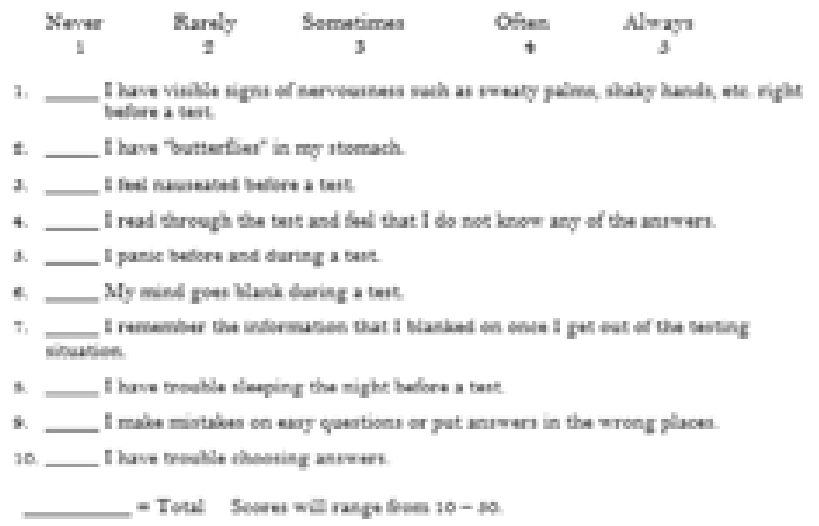

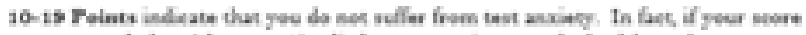
wan entremely lew (clione to 10 , a little meen anxinty may be healthy to keep joe feresed and se get peer Heed Gening dering anema.

s0-s3 Peints ahews that although yow enhibit seme of the characteriatice of tant. encing, the level of varas and tenaien is grobally healdhy.

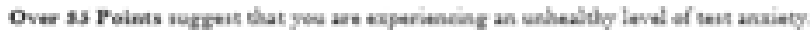

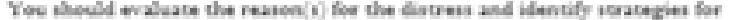

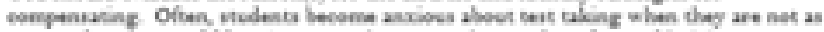

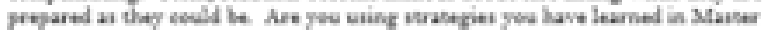

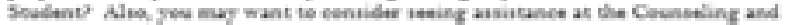

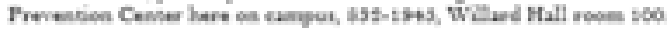

(b)

Figure 5. TSelf-efficacy questionnaire (a) and anxiety test questionnaire (b)

A summation of responses determined the self-efficacy of the whether the students believed the learning protocol was beneficial. This questionnaire was derived from the
"Academic Self-Efficacy Subscale from Self-Efficacy Questionnaire for Children" (Muris, 2001). Figure 5 provides the two questionnaires used in this study.

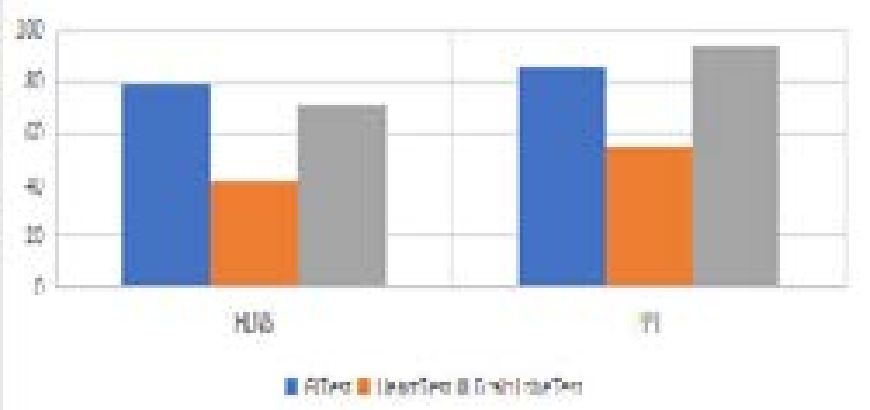

Figure 6. GI Test, Heart Test, and Brain Lobe Test results of PPT group and HLNS group 


\section{Results and Discussion}

Figure 6 displays the average score of the two participant groups from the three tests. The PPT group had a higher exam performance for all three areas of the body studies compared to the performance of the HLNS group.

A total of 22 students finished the PPT (11 students) and HLNS (11 students) Learning Anatomy study. A g-power analysis was completed, with a determined sample size of 16 was expected at an alpha set at $\mathrm{p}<0.05$ and power at .8 , with a beta at 0.2 . IBM's SPSS software was used to measure independent means, standard deviations, and perform t-test analyses (Table 2). A Levene's Test of Equality of Variances was used to assess variances, with significance greater than 0.05 .

In the systems self-efficacy questionnaire, the HLNS group showed significantly higher results compared to the PPT group, $\mathrm{U}=28$, $\mathrm{p}$ $=0.034$. The HLNS group had a higher score on self-efficacy level regardless of previous human physiology experience. Questionnaire scores indicate that there was a preference for the HLNS HoloAnatomy experience. In addition, the PPT group showed a significantly

Table 2 Mean and standard deviation of PPT and HLNS groups

\begin{tabular}{|c|c|c|c|c|c|}
\hline \multicolumn{6}{|c|}{ Group statistics } \\
\hline & Group ID & $\mathrm{N}$ & Mean & Std. Deviation & Std. Error Mean \\
\hline \multirow{2}{*}{ GI Test } & PPT & 11 & 85.27 & 22.163 & 6.683 \\
\cline { 2 - 6 } & HLNS & 11 & 79.27 & 21.845 & 6.587 \\
\hline \multirow{2}{*}{ Heart Test } & PPT & 11 & 54.64 & 32.751 & 9.875 \\
\cline { 2 - 6 } & HLNS & 11 & 42.09 & 23.939 & 7.218 \\
\hline \multirow{2}{*}{$\begin{array}{c}\text { Brain Lobe } \\
\text { Test }\end{array}$} & PPT & 11 & 93.91 & 11.220 & 3.383 \\
\cline { 2 - 6 } & HLNS & 11 & 70.55 & 29.039 & 8.756 \\
\hline Test & PPT & 11 & 29.55 & 4.321 & 1.303 \\
\cline { 2 - 6 } Anxiety & HLNS & 11 & 24.27 & 3.609 & 1.113 \\
\hline System SE & PPT & 11 & 63.36 & 17.603 & 5.307 \\
\cline { 2 - 6 } Survey & HLNS & 11 & 78.45 & 13.171 & 3.971 \\
\hline
\end{tabular}

Table 3 Non-parametric test results for each hypothesis - Mann-Whitney U Test

\begin{tabular}{|c|c|c|c|c|}
\hline \multicolumn{7}{|c|}{ Hypothesis Test Summary } \\
\hline No. & Null Hypothesis & Test & Sig. & Decision \\
\hline 1 & $\begin{array}{c}\text { The distribution of Test Anxiety is the } \\
\text { same across categories of Group ID }\end{array}$ & $\begin{array}{c}\text { Independent Samples } \\
\text { Mann-Whitney U Test }\end{array}$ & 0.008 & $\begin{array}{c}\text { Reject the null } \\
\text { hypothesis }\end{array}$ \\
\hline 2 & $\begin{array}{c}\text { The distribution of GI test is the same } \\
\text { across categories of Group ID }\end{array}$ & $\begin{array}{c}\text { Independent Samples } \\
\text { Mann-Whitney U Test }\end{array}$ & 0.243 & $\begin{array}{c}\text { Retain the null } \\
\text { hypothesis }\end{array}$ \\
\hline 3 & $\begin{array}{c}\text { The distribution of Heart test is the same } \\
\text { across categories of Group ID }\end{array}$ & $\begin{array}{c}\text { Independent Samples } \\
\text { Mann-Whitney U Test }\end{array}$ & 0.519 & $\begin{array}{c}\text { Retain the null } \\
\text { hypothesis }\end{array}$ \\
\hline 5 & $\begin{array}{c}\text { The distribution of Brain Lobe test is the } \\
\text { same across categories of Group ID }\end{array}$ & $\begin{array}{c}\text { Independent Samples } \\
\text { Mann-Whitney U Test }\end{array}$ & 0.016 & $\begin{array}{c}\text { Reject the null } \\
\text { hypothesis }\end{array}$ \\
\hline $\begin{array}{c}\text { The distribution of System SE Survey is } \\
\text { the same across categories of Group ID }\end{array}$ & $\begin{array}{c}\text { Independent Samples } \\
\text { Mann-Whitney U Test }\end{array}$ & 0.034 & $\begin{array}{c}\text { Reject the null } \\
\text { hypothesis }\end{array}$ \\
\hline
\end{tabular}


higher test anxiety score, $\mathrm{U}=100, \mathrm{p}=0.01$, but were still within healthy levels of stress and tension (Cassady \& Johnson, 2002). Lastly, while average test scores were better for the PPT group across all three tests, a significant difference was only found for the Brain Lobe test, $U=96.5, p=0.016$. Table 3 highlights all statistical tests that were evaluated and their results.

Test anxiety is a common stressor exhibited in many students on college campuses at the end of a semester. One physiological factor that anxiety can induce is cognitive interference or CI. CI is the continuation of extraneous thoughts that can interfere with tasks that the individual is trying to accomplish (Breslau, 2001). The introduction of video games, virtual reality
(VR), AR, and mixed reality systems are being presented as supplemental support to traditional pharmacological and counseling interventions to mitigate CI (Breslau, 2001).

The purpose of this study was to build off existing literature findings and test AR versus the more traditional classroom presentation of human anatomy in order to determine the introduction of new technology could be used to help improve memory and reduce test anxiety. While the HLNS teaching method did not seem to aid student memory compared to the traditional PPT method based on exam results, the significant difference between the two groups' systems self-efficacy (Figure 7) and test anxiety results does provide a potentially positive narrative toward improving the learning environment for the

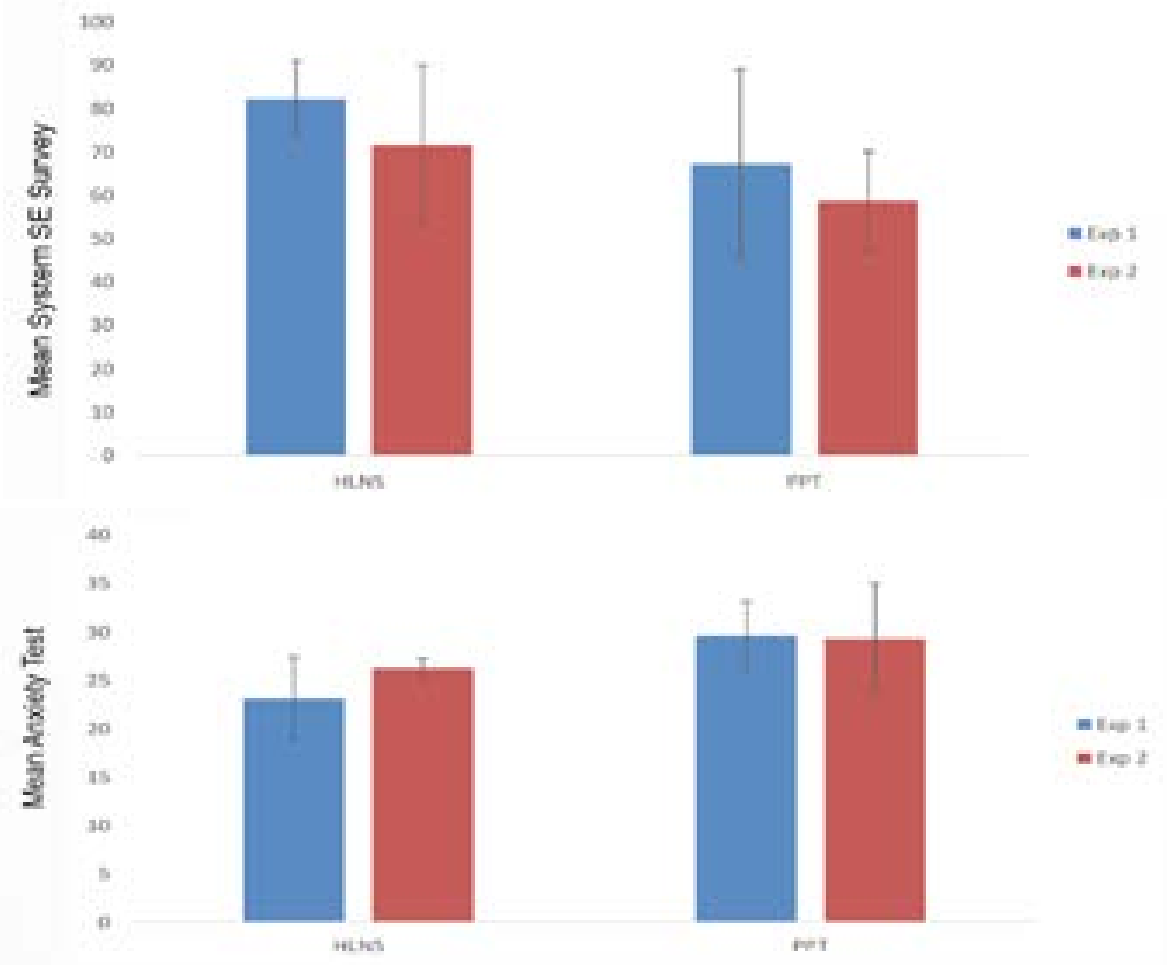

Figure 7. HLNS group and PPT group results for the SEQ-C survey and Anxiety Test based on previous anatomy experience; Experience 1 group had no previous anatomy experience while Experience 2 group did. 
student. Including AR technology which may positively alter study habits and preparation for future tests. As previous research has indicated (Rizzo et al., 2014), low levels of self-efficacy are an indicator of anxiety disorder symptoms. The higher self-efficacy response while using the HLNS may be due to the active learning environment thereby reduce negative symptoms through an improved selfefficacy.

As expected with being a pilot study, there were limitations. Resource limitations due to only having one HLNS impacted the number of recruited participants. Also, due to the utilization of new technology, the methods were constrained to the limited amount of educational applications available and the features of those applications. Lastly, the participants who reported as not having taken collegiate-level anatomy or biology class could still have been exposed to the provided topics before participating in this study via high school or some other educational forum. Therefore, knowing if the participants learned this information strictly from the materials provided to them or some other experience would be difficult to prove or determine.

\section{Conclusion}

This study evaluated AR-based learning technology against a more traditional technology, PPT, by teaching anatomy and physiology information to students. Twentytwo undergraduate student participants were divided into two groups, each with their own study methods (PPT versus HLNS). The experiment provided the same anatomybased content and learning duration for the two groups vie the respective educational medium to determine if there was a difference in memory recall of the material. Recall was determined based on the students' exam results where they were asked to demonstrate how much they'd learned about three anatomy the sections: (a) GI, (b) heart, and (c) brain lobe. In addition to memory, the experiment used questionnaires to assess student test anxiety and systems self-efficacy after the test was taken. The results of the exam demonstrate that, for this study, the use of the HLNS did not have a positive effect on test scores versus the more traditional PPT method. In fact, all exam score averages were higher for the PPT group with a significant effect for the brain lobe test. But the results of the test anxiety and self-efficacy questionnaire demonstrate a positive correlation for using HLNS in learning environments. Selfefficacy scores were significantly higher and test anxiety scores were significantly lower for the HLNS group compared to the PPT group. This presents an argument that an ARbased learning method has potential to be applied in learning environments - at least in those environments specific to anatomy and physiology material. Although this pilot study has technology utilization and resource limitations as well as a limited number and educational demographic of participants, it still demonstrates the benefits of AR-based learning media in anxiety and self-efficacy improvement. 


\section{References}

Antonioli, M., Blake, C., \& Sparks, K. (2014). Augmented reality applications in education. The Journal of Technology Studies, 96-107. https://doi.org/10.21061/ jots.v40i2.a.4

Azuma, R. T. (1997). A survey of augmented reality. Presence: Teleoperators \& Virtual Environments, 6(4), 355-385. https://doi. org/10.1162/pres.1997.6.4.355

Baus, O., \& Bouchard, S. (2014). Moving from virtual reality exposure-based therapy to augmented reality exposurebased therapy: a review. Frontiers in human neuroscience, 8,112 . https://doi. org/10.3389/fnhum.2014.00112

Botella, C., Riva, G., Gaggioli, A., Wiederhold, B. K., Alcaniz, M., \& Banos, R. M. (2012). The present and future of positive technologies. Cyberpsychology, Behavior, and Social Networking, 15(2), 78-84. https://doi.org/10.1089/ cyber.2011.0140

Breslau, N. (2001). The epidemiology of posttraumatic stress disorder: what is the extent of the problem? The Journal of clinical psychiatry.

Cassady, J. C., \& Johnson, R. E. (2002). Cognitive test anxiety and academic performance. Contemporary educational psychology, 27(2), 270-295. https://doi. org/10.1006/ceps.2001.1094

Collins, A., \& Halverson, R. (2018). Rethinking education in the age of technology: The digital revolution and schooling in America. Teachers College Press.

Dunleavy, M., Dede, C., \& Mitchell, R. (2009). Affordances and limitations of immersive participatory augmented reality simulations for teaching and learning. Journal of science Education and Technology, 18(1), 7-22. https://doi. org/10.1007/s10956-008-9119-1

Elangovan, T., \& Ismail, Z. (2014). The effects of $3 \mathrm{D}$ computer simulation on biology students' achievement and memory retention. In Asia-Pacific Forum on Science Learning \& Teaching, 15(2).

Enyedy, N., Danish, J. A., Delacruz, G., \& Kumar, M. (2012). Learning physics through play in an augmented reality environment. International journal of computer-supported collaborative learning, 7(3), 347-378. https://doi. org/10.1007/s11412-012-9150-3

Horne-Moyer, H. L., Moyer, B. H., Messer, D. C., \& Messer, E. S. (2014). The use of electronic games in therapy: a review with clinical implications. Current psychiatry reports, 16(12), 520. https:// doi.org/10.1007/s11920-014-0520-6

Irwansyah, F. S., Yusuf, Y. M., Farida, I., \& Ramdhani, M. A. (2018). Augmented reality (AR) technology on the android operating system in chemistry learning. In IOP conference series: Materials science and engineering, 288(1), 012068. https://doi.org/10.1088/1757899X/288/1/012068

Johnson, L., Levine, A., Smith, R., \& Stone, S. (2010). The 2010 Horizon Report. New Media Consortium. 6101 West Courtyard Drive Building One Suite 100, Austin, TX 78730.

Johnson, L., Smith, R., Willis, H. Levine, A., \& Haywood, K. (2011). The 2011 Horizon Report. New Media Consortium. 6101 West Courtyard Drive Building One Suite 100, Austin, TX 78730.

Lawrence, S., De Silva, M., \& Henley, R. (2020). Sports and games for posttraumatic stress disorder (PTSD). Cochrane Database of Systematic Reviews, (1).

Marks, I. M., Baer, L., Greist, J. H., Park, J. M., Bachofen, M., Nakagawa, A., 
... \& Mantle, J. M. (1998). Home selfassessment of obsessive-compulsive disorder: Use of a manual and a computerconducted telephone interview: Two UK-US studies. The British Journal of Psychiatry, 172(5), 406-412. https://doi. org/10.1192/bjp.172.5.406

Moustafa, H., Kenn, H., Sayrafian, K., Scanlon, W., \& Zhang, Y. (2015). Mobile wearable communications [Guest Editorial]. IEEE Wireless Communications, 22(1), 10-11. https:// doi.org/10.1109/MWC.2015.7054713

Muris, P. (2002). Relationships between self-efficacy and symptoms of anxiety disorders and depression in a normal adolescent sample. Personality and individual differences, 32(2), 337 348. https://doi.org/10.1016/S01918869(01)00027-7

Newman, M. G., Kenardy, J., Herman, S., \& Taylor, C. B. (1997). Comparison of palmtop-computer-assisted brief cognitive-behavioral treatment to cognitive-behavioral treatment for panic disorder. Journal of consulting and clinical psychology, 65(1), 178. https://doi. org/10.1037/0022-006X.65.1.178

Newman, M. G., Szkodny, L. E., Llera, S. J., \& Przeworski, A. (2011). A review of technology-assisted self-help and minimal contact therapies for anxiety and depression: is human contact necessary for therapeutic efficacy? Clinical psychology review, 31(1), 89-103. https:// doi.org/10.1016/j.cpr.2010.09.008

Nist, P., \& Diehl, M. (1990). PHCC test anxiety questionnaire.

Opriş, D., Pintea, S., García-Palacios, A., Botella, C., Szamosközi, Ş., \& David, D. (2012). Virtual reality exposure therapy in anxiety disorders: a quantitative metaanalysis. Depression and anxiety, 29(2), 85-93. https://doi.org/10.1002/da.20910

Rizzo, A., Hartholt, A., Grimani, M., Leeds,
A., \& Liewer, M. (2014). Virtual reality exposure therapy for combat-related posttraumatic stress disorder. Computer, 47(7), 31-37. https://doi.org/10.1109/ MC.2014.199

Rothbaum, B. O., Hodges, L. F., Kooper, R., Opdyke, D., Williford, J. S., \& North, M. (1995). Virtual reality graded exposure in the treatment of acrophobia: A case report. Behavior therapy, 26(3), 547-554. https:// doi.org/10.1016/S0005-7894(05)80100-5

Salmi, H., Thuneberg, H., \& Vainikainen, M. P. (2017). Making the invisible observable by Augmented Reality in informal science education context. International Journal of Science Education, Part B, 7(3), 253-268. https://doi.org/10.1080/21548455.2016.12 54358

Walshe, D. G., Lewis, E. J., Kim, S. I., O'Sullivan, K., \& Wiederhold, B. K. (2003). Exploring the use of computer games and virtual reality in exposure therapy for fear of driving following a motor vehicle accident. CyberPsychology \& Behavior, 6(3), 329-334. https://doi. org/10.1089/109493103322011641

Wright, J. H., Salmon, P., Wright, A. S., \& Beck, A. T. (1995). Cognitive therapy: A multimedia learning program. In annual meeting of the American Psychiatric Association, Miami Beach, FL.

Wright, J. H., Wright, A. S., Salmon, P., Beck, A. T., Kuykendall, J., Goldsmith, L. J., \& Zickel, M. B. (2002). Development and initial testing of a multimedia program for computer-assisted cognitive therapy. American Journal of Psychotherapy, 56(1), 76-86. https://doi.org/10.1176/appi. psychotherapy.2002.56.1.76

Wrzesien, M., Alcañiz, M., Botella, C., Burkhardt, J. M., Bretón-López, J., Ortega, M., \& Brotons, D. B. (2013). The therapeutic lamp: treating small-animal phobias. IEEE computer graphics and applications, 33(1), 80-86. https://doi. 
org/10.1109/MCG.2013.12

Wrzesien, M., Burkhardt, J. M., Alcañiz, M., \& Botella, C. (2011, September). How technology influences the therapeutic process: a comparative field evaluation of augmented reality and in vivo exposure therapy for phobia of small animals. In IFIP Conference on Human-Computer Interaction (pp. 523-540). Springer, Berlin, Heidelberg. https://doi.org/10.1007/978-3642-23774-4_43

Yuen, S. C. Y., Yaoyuneyong, G., \& Johnson, E. (2011). Augmented reality: An overview and five directions for AR in education, Journal of Educational Technology Development and Exchange (JETDE), 4(1), 11. https://doi. org/10.18785/jetde. 0401.10

\section{Contact the Author}

\section{Chen Chen}

$\mathrm{PhD}$

Department of Sustainable Bioproducts

Mississippi State University

Mississippi State, MS

Email: cc3686@msstate.edu

\section{Lei Zhang}

$\mathrm{PhD}$

Department of Civil \& Environmental Engineering

Mississippi State University

Mississippi State, MS

Email:1z218@msstate.edu

\section{Tony Luczak}

$\mathrm{PhD}$ Candidate

Department of Industrial \& Systems Engineering

Mississippi State University

Mississippi State, MS

Email: luczak@ise.msstate.edu

\section{Eboni Smith}

$\mathrm{PhD}$

Department of Industrial \& Systems Engineering

Mississippi State University

Mississippi State, MS

Email: ens123@msstate.edu

\section{Reuben F. Burch V}

Assistant Professor

Department of Industrial \& Systems Engineering

Mississippi State University

Mississippi State, MS

Email: rfb2@msstate.edu 